\title{
Observation of Phase Transformations in High-temperature Chamber under Microscope Ob- jective Lens
}

\author{
Michal Peković ${ }^{1}$, Kateřina Opatová ${ }^{1}$, Kateřina Rubešová ${ }^{1}$, Tomáš Janda ${ }^{1}$, Hana Jirková ${ }^{1}$, Radovan Bureš ${ }^{2}$ \\ ${ }^{1}$ Faculty of Mechanical Engineering - Regional Technological Institute, University of West Bohemia, \\ Univerzitní 8, 30614 Pilsen, Czech Republic \\ ${ }^{2}$ Institute of Materials Research, Slovak Academy of Science, Watsonova 47, 04001 Košice, Slovak Republic \\ E-mail: pekovicm@rti.zcu.cz, opatovak@rti.zcu.cz, krubesov@rti.zcu.cz, jandat@rti.zcu.cz, hstankov@rti.zcu.cz, \\ rbures@saske.sk
}

Today, extensive information on a particular material can be obtained from its chemical composition using various computer programs. Such information includes phase transformation temperatures, such as Ac1 and Ac3 or the Ms and Mf, as well as the entire austenite decomposition sequence, as shown in TTT and CCT diagrams. When steel is heated, austenite grains begin to form, grow and eventually coarsen. On cooling, these grains decompose into pearlite, ferrite, cementite and hardening phases. Transformations of this kind are well understood nowadays, namely the ways the individual phases form and the rates and temperatures involved. Yet, in-situ visual recordings of such transformations are relatively rare. Using the Linkam TS1400XY heating stage, which is capable to heat samples up to $1400^{\circ} \mathrm{C}$ and is integrated in an optical microscope featuring objective lenses with modified working distances, these phase transformations can be observed directly. This paper explores the potential of the heating stage for studying various materials and their specific heat treatments. It also discusses the method of sample preparation for use in the heating stage placed in an optical microscope.

Keywords: heating stage, phase transformations, optical microscopy, heat treatment

\section{Introduction}

Observation of phase transformations in steels can provide a range of useful information for designing heat treatment sequences. Using chemical composition data, computer programs can calculate many characteristics of a material. Phase transformation temperatures can be determined and the TTT and CCT diagrams - which describe austenite decomposition - can be constructed [1]. A number of theoretical and other studies on phase transformations are available which describe the conditions for formation of individual phases, transformation mechanisms and the exothermic or endothermic nature of the transformations. Unfortunately, there are not many visual recordings of the actual progress of phase transformations. Such recordings can be produced using the TS1400XY heating stage from the Linkam company [2].

With the aid of this attachment, formation and growth of austenite grains can be observed as the sample is brought to the austenitising temperature. The samples can be heated to up to $1400^{\circ} \mathrm{C}$ at the maximum rate of $200^{\circ} \mathrm{C} / \mathrm{s}$. Samples can also be observed during cooling, while developing various microstructural constituents, depending on the cooling rate. The maximum cooling rate achievable by the heating stage is $200^{\circ} \mathrm{C} / \mathrm{s}$. The heating and cooling rates are input as parameters into simple thermal profiles which can be defined using the heating stage's display or using computer software [1]. The software can generate a temperature-time graph as a record of the thermal profile. The heating stage is fitted with a Peltier cell which provides cooling of important and heat-sensitive components via a system of hoses. The chamber of the heating stage can be filled with a protective gas: nitrogen or argon (Fig. 1, right) [3].

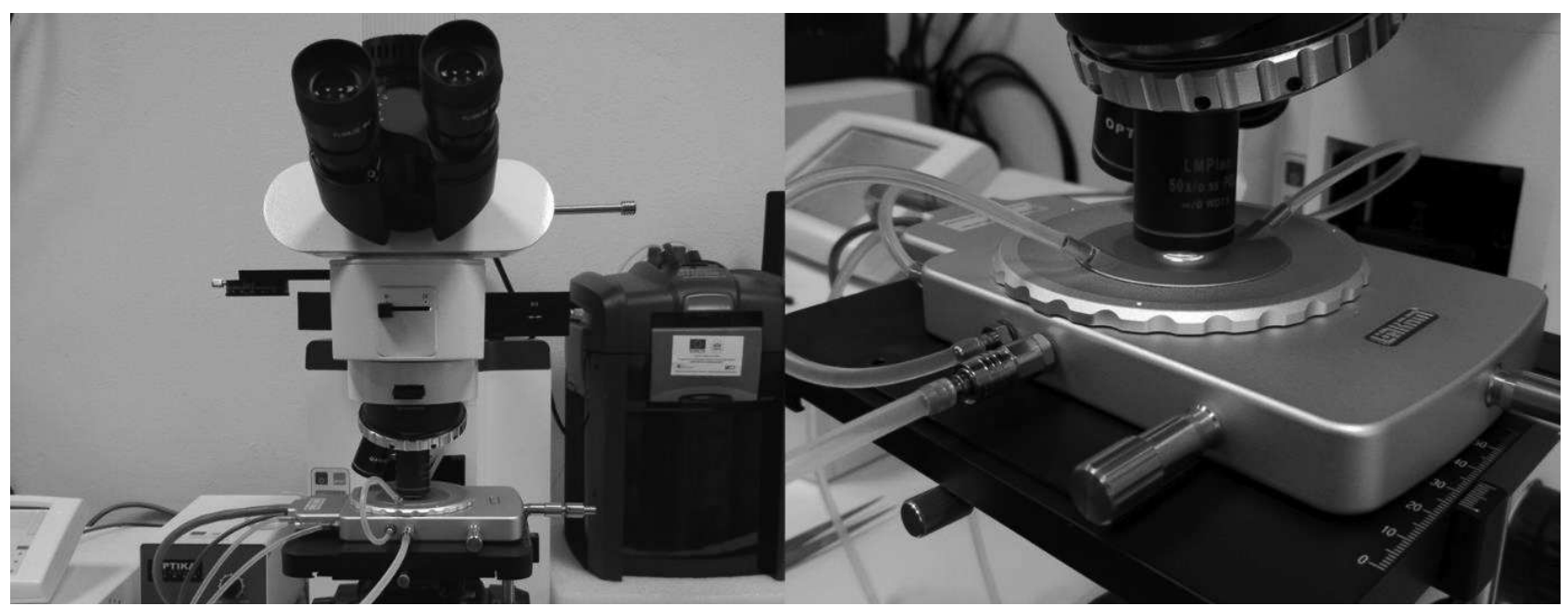

Fig. 1 Microscope with an integrated heating stage (left), the chamber during heating to a high temperature (right) 
The heating stage can be placed onto the stage of a microscope which features objective lenses with $10 \times, 20 \times$ and $50 \times$ magnifications (Fig. 1, left). All these objective lenses have longer working distances which enables focusing onto the sample inside the heating stage chamber. The chamber itself is provided with a miniature stage which moves the sample in the $\mathrm{X}$ and $\mathrm{Y}$ directions even during treatment [4].

The maximum size of samples is $5 \times 5 \mathrm{~mm}$ and their maximum possible thickness is $0.7 \mathrm{~mm}$. For better-focused images, the surface to be observed should be prepared as a metallographic section. Inside the chamber, the sample is placed on a heat-resistant glass plate which is moved by the XY miniature stage to the position for heating (Fig. 2). The sample can be cooled faster by rapid withdrawal from the heating position, after which, however, observation and recording are not possible any more [5].

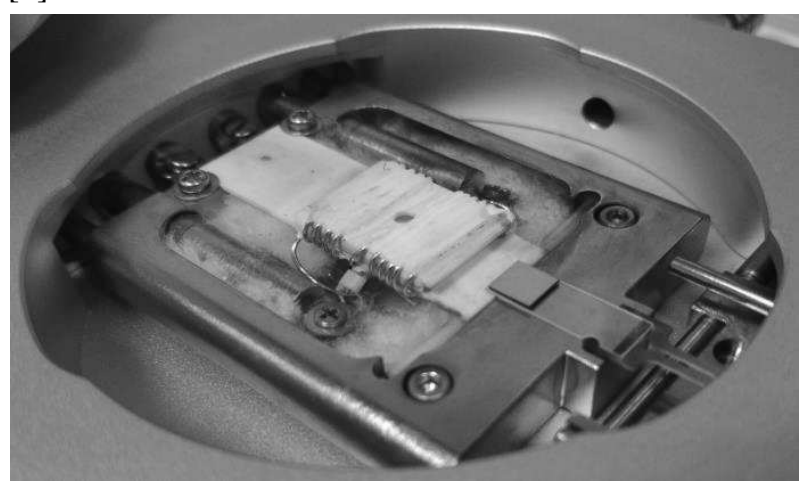

Fig. 2 Interior of the heating stage chamber with a sample placed on a heat-resistant glass plate

\section{Experiments}

The purpose of these experiments was to explore the capabilities of the heating stage at various heating and cooling rates. An additional goal was to find the appropriate sample thickness and sample preparation methods for this observation.

In these experiments, phase transformations in various materials were studied (Tab. 1). The treatment applied to 42SiCr high-strength steel was the Q\&P process. CMnSi TRIP steel was intercritically annealed. In the $\mathrm{X} 210 \mathrm{Cr} 12$ tool steel, decomposition of austenite grains produced by semi-solid processing was observed during holds at various temperatures. Examples of temperature profiles for these treatments are given in Fig. 3.

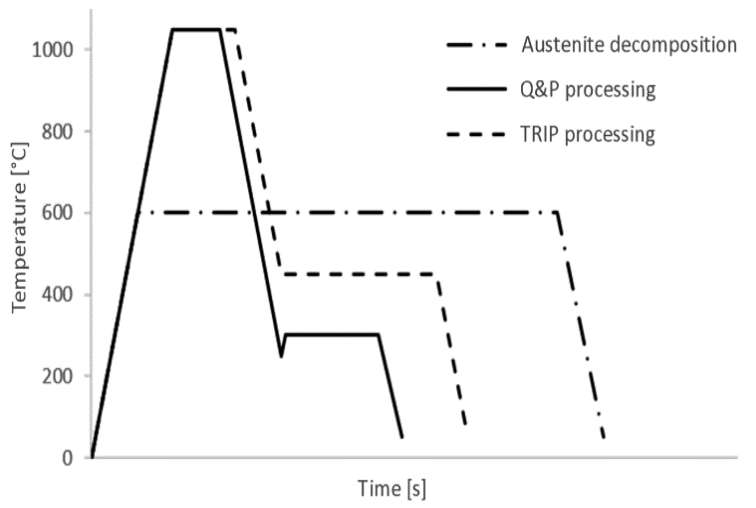

Fig. 3 Diagram of heat treatment routes

Tab. 1 Chemical composition of the experimental steels [6]

\begin{tabular}{|c|c|c|c|c|c|c|c|c|}
\hline & $\mathbf{C}$ & $\mathbf{S i}$ & $\mathbf{M n}$ & $\mathbf{C r}$ & $\mathbf{M o}$ & $\mathbf{N b}$ & $\mathbf{P}$ & $\mathbf{S}$ \\
\hline 42SiCr & 0.42 & 2.03 & 0.56 & 1.33 & 0.16 & 0.03 & 0.005 & 0.003 \\
\hline CMnSi TRIP & 0.21 & 1.797 & 1.449 & 0.008 & 0.02 & 0.03 & 0.008 & 0.005 \\
\hline X210Cr12 & $1.8-2.05$ & $0.2-0.45$ & $0.2-0.45$ & $11-12.5$ & - & - & $\max 0.03$ & $\max$ \\
& & & & - & & & \\
\hline
\end{tabular}

\subsection{Sample preparation}

The dimensions of samples for the heating stage were chosen as $4 \times 4 \mathrm{~mm}$, with the thickness of $0.5 \mathrm{~mm}$. For ease and accuracy of focusing, emphasis was placed on preparing the faces of samples as parallel planes. The first preparation step was grinding in a grinder with a magnetic table. It was followed by conventional metallographic preparation comprising grinding and polishing.

The samples were prepared to three different conditions. The first one was obtained by polishing on a polishing cloth using a suspension of $1 \mu \mathrm{m}$ particles. The second condition was produced by etching with $3 \%$ nital. The last one resulted from final polishing using colloidal silica.

\subsection{Design of heat treatment sequences}

Prior to the actual experimental treatment, several preliminary sequences were performed in order to determine temperatures and times for full austenitisation.

42SiCr high-strength steel was heat treated using the $\mathrm{Q} \& \mathrm{P}$ process. The material was soaked at an austenitising temperature and quenched below the martensite start temperature. Then it was reheated above the quenching temperature and held. Soaking temperatures of $950^{\circ} \mathrm{C}$, $1050^{\circ} \mathrm{C}$ and $1100^{\circ} \mathrm{C}$ were used. The quenching temperatures were $150^{\circ} \mathrm{C}, 200^{\circ} \mathrm{C}$ and $250^{\circ} \mathrm{C}$ and the partitioning temperatures were $200^{\circ} \mathrm{C}, 250^{\circ} \mathrm{C}$ and $300^{\circ} \mathrm{C}$.

The CMnSi TRIP steel was austenitised at $1050^{\circ} \mathrm{C}$ for 240 seconds and then intercritically annealed at $400^{\circ} \mathrm{C}$, $425^{\circ} \mathrm{C}$ and $450^{\circ} \mathrm{C}$ for 600 seconds.

In the $\mathrm{X} 210 \mathrm{Cr} 12$ tool steel, the decomposition of austenite grains was observed at several temperatures between $500^{\circ} \mathrm{C}$ and $800^{\circ} \mathrm{C}$ with a step of $100^{\circ} \mathrm{C}$ and the time at temperature of 30 minutes [7].

\section{Results and discussion}

Etching with nital proved to be the most suitable sample preparation method from those proposed for observing the phase transformations. The etch has revealed the initial microstructures of materials. The microstructure then underwent changes during heating 
and cooling. In the specimens prepared by mere polishing, microstructural changes during heating and cooling were impossible to observe using a microscope. In the specimens prepared by means of polishing with colloidal silica, partly revealed grain boundaries could be observed. [8]
After several experiments, it was found that the material was oxidising quickly owing to high temperature. The resulting oxide layer precluded observation of microstructure and phase transformations. Hence, protective argon gas was introduced into the chamber in all subsequent experiments to prevent oxidation. [9]
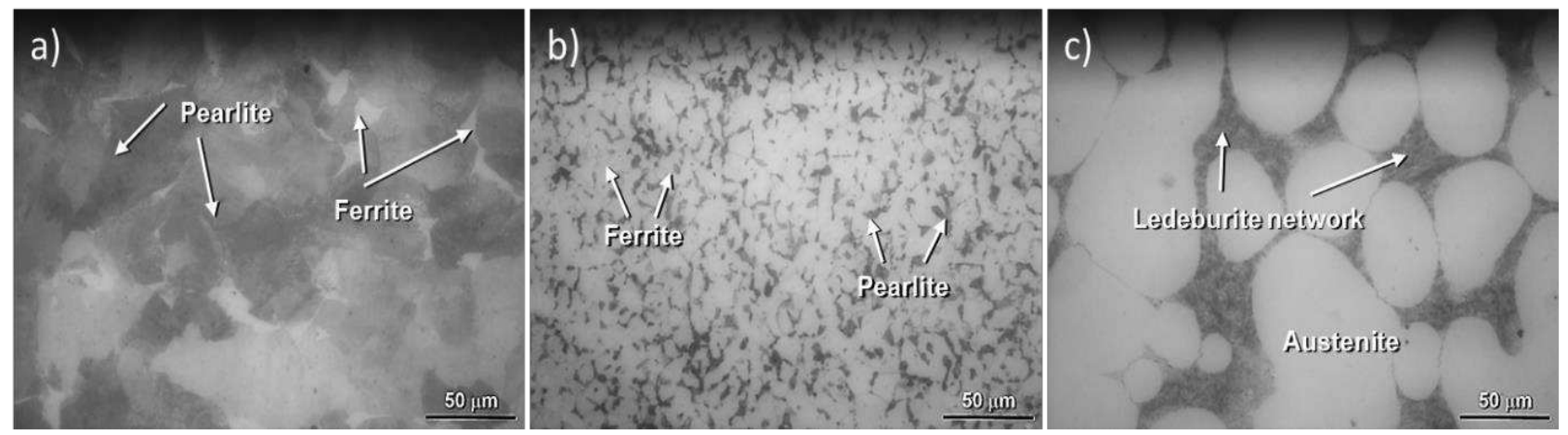

Fig. 4 Initial microstructure of experimental materials: a) 42SiCr, b) CMnSi TRIP, c) X210Cr12

The initial microstructure of $42 \mathrm{SiCr}$ consisted of ferrite and pearlite (Fig. 4a). First, the austenitising temperature was determined as $1100^{\circ} \mathrm{C}$. At this temperature, distinct austenite grains formed. The holding time at this temperature was set at 240 seconds. The micrograph of this material after isothermal holding is shown in Fig. 5a. After holding at the austenitising temperature, the sample was cooled at $200^{\circ} \mathrm{C} / \mathrm{min}$. At $500^{\circ} \mathrm{C}$, a growth of a phase, probably Widmanstätten ferrite/bainite, was observed
(Fig. 5b). In the next step, the material was cooled to the quenching temperature, which in this case was $200^{\circ} \mathrm{C}$. Between $300^{\circ} \mathrm{C}$ and the quenching temperature, dramatic microstructural changes occurred, possibly due to martensite transformation. After that, the material was held at a partitioning temperature of $250^{\circ} \mathrm{C}$ (Fig. $5 \mathrm{c}$ ). It was then cooled to room temperature and no distinct changes were found in the microstructure.
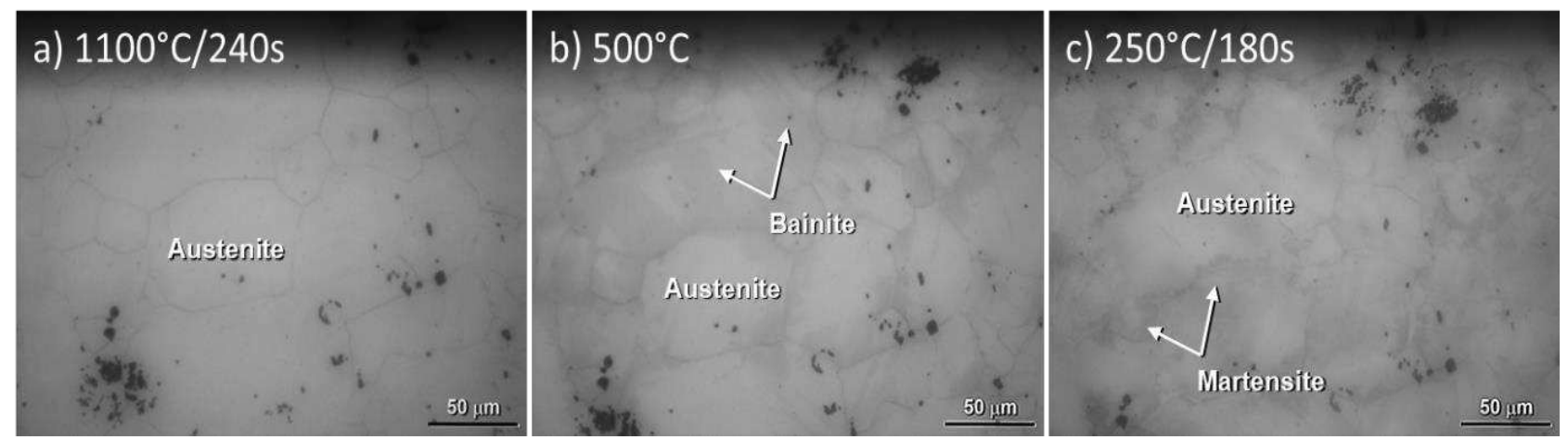

Fig. 5 The 42SiCr steel in the course of heat treatment: a) end of soaking, b) cooling, $500^{\circ} \mathrm{C}$, c) at the end of the partitioning step

The CMnSi TRIP steel had an initial ferritic-pearlitic microstructure (Fig. 4b). First, the appropriate austenitising temperature was sought by testing the temperatures of $1000^{\circ} \mathrm{C}, 1050^{\circ} \mathrm{C}$ and $1100^{\circ} \mathrm{C}$. Austenitising parameters were then set at $1050^{\circ} \mathrm{C}$ and 180 seconds. At this temperature, new distinct austenite grain boundaries and a small amount of undissolved pearlite were visible (Fig. 6a). After austenitising, the sample was cooled at the maximum achievable rate to the isothermal holding temperature which, in the case of TRIP steels, is in the bainitic transformation region. Here, it was $400^{\circ} \mathrm{C}$. The time at this temperature was 600 seconds. At the beginning of the isothermal holding step, the microstructure was a mixture of ferrite with small fractions of pearlite, retained austenite and bainite (Fig. 6b). The retained austenite grains were located on the boundaries of the ferrite grains and between bainite laths. After the hold at bainitic transformation temperature had ended, martensite was formed. Strings of small retained austenite grains remained visible on prior austenite grain boundaries. The retained austenite grains were also found between ferrite grains, some of which were already transformed to the M-A constituent. Small amount of bainite was visible as well. The figure also illustrates the fact that despite the use of protective atmosphere, surface oxidation took place during long holding times, obscuring the microstructure to some extent (Fig. 6c). 

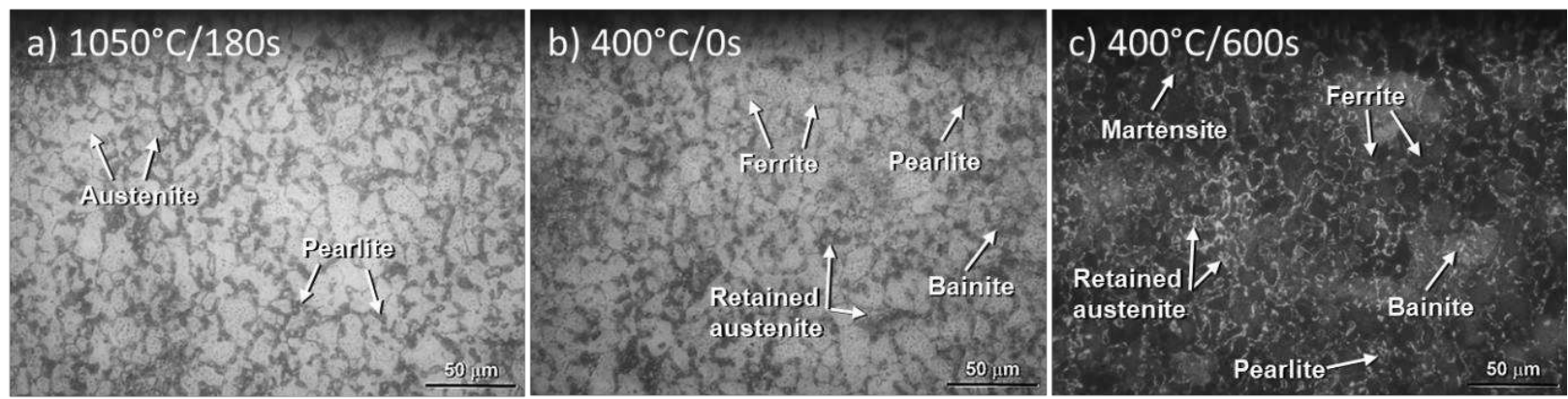

Fig. 6 The CMnSi TRIP steel during heat treatment: a) end of the soaking step, b) start of isothermal holding, c) end of isothermal holding at bainitic transformation temperature

The initial microstructure of $\mathrm{X} 210 \mathrm{Cr} 12$ consisted of polyhedral austenite grains embedded in a ledeburite network (Fig. 4c). It formed after the material had been heated to the semi-solid region and water-quenched. This material was chosen for exploring the stability of metastable austenite grains and for studying their decomposition during holding at various temperatures. The changes observed during this heat treatment were less distinct than in the other materials. In fact, the only visible process was a darkening of the ledeburite network (Fig. 7). Without more detailed examination, it is impossible to determine whether any changes actually took place in the microstructure or whether a mere surface oxidation was occurred.
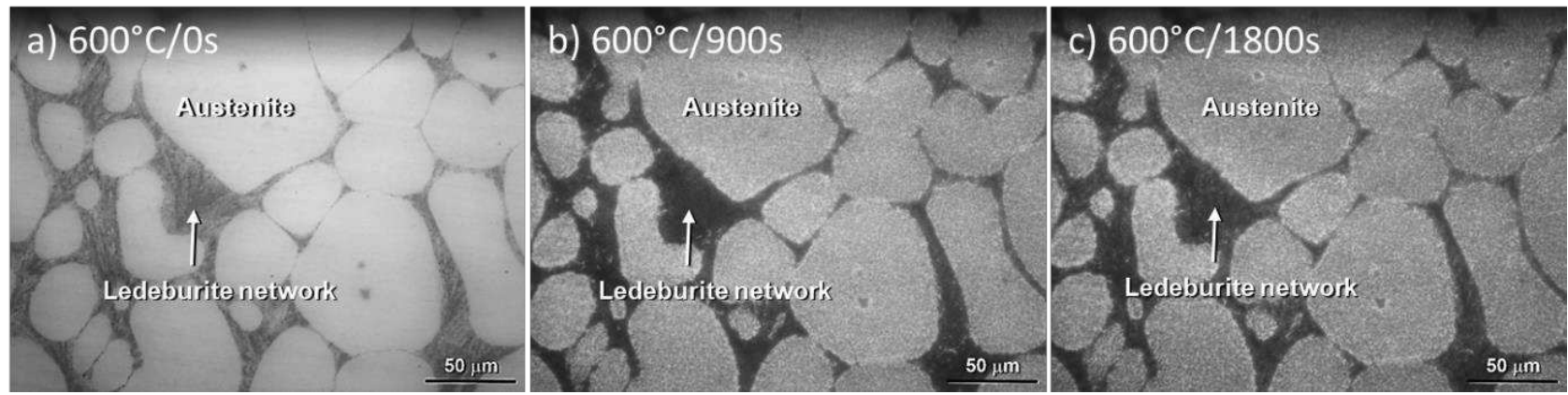

Fig. 7 The X210Cr12 during heat treatment with various soaking times at $600^{\circ} \mathrm{C}$

\section{Conclusion}

Using a TS1400XY heating stage, two experimental high-strength steels, 42SiCr and CMnSi TRIP, and the $\mathrm{X} 210 \mathrm{Cr} 12$ tool steel were heat treated. Q\&P processing was applied to the $42 \mathrm{SiCr}$ steel. The CMnSi TRIP steel was treated by intercritical annealing. Decomposition of austenite grains was explored in the $\mathrm{X} 210 \mathrm{Cr} 12$ tool steel.

In $42 \mathrm{SiCr}$, growth of austenite grains was observed during a 240 -second hold at $1100^{\circ} \mathrm{C}$. In the course of cooling at the maximum rate of $200^{\circ} \mathrm{C} / \mathrm{min}$, nucleation of pearlite at triple points was visible at approximately $600^{\circ} \mathrm{C}$. Formation of Widmanstätten ferrite was documented on video recordings. Very distinct and rapid microstructural changes were visible below $300^{\circ} \mathrm{C}$. They probably involved the growth of martensite needles.

Micrographs of the CMnSi TRIP steel taken at its austenitising temperature showed distinct austenite grain boundaries and a small amount of remaining undissolved pearlite. At the beginning of isothermal holding in the bainitic transformation region, the microstructure was a mixture of austenite, martensite and a small amount of bainite. After this hold had ended, a large volume of martensite formed. In addition, the material contained a small volume of bainite and some grains of retained austenite.
Micrographs of X210Cr12 showed darkening of the ledeburite network and microstructural changes in the interior of austenite grains. One possible cause of this is oxidation of the surface during long-time isothermal holding. This is why it was impossible to determine the exact changes which were taking place in the material.

Using a heating stage integrated in a light microscope enabled the behaviour of various materials to be observed during heat treatment. It provided new findings which help clarify the processes taking place in individual stages of heat treatment.

\section{Acknowledgement}

This paper includes results achieved within the project SGS-2016-060 Research of Modern AHS Steels and Innovative Processing for their Manufacturing. The project is subsidised from specific resources of the state budget for research and development.

\section{References}

[1] ESPOSITO, R., KLEBESZ, R., BARTOLI, O., KLYUKIN, Y., MONCADA, D., DOHERTY, A., BODNAR, R. (2012). Application of the Linkam 
TS1400XY heating stage to melt inclusion studies. In: Central European Journal of Geosciences, Vol. 4, pp. 208-218.

[2] LEE, J., SHIBATA, K., ASAKURA, K., MASUMOTO, Y. (2002). Observation of $\gamma \rightarrow \alpha$ Transformation in Ultralow-carbon Steel under a High Temperature Optical Microscope. In: ISIJ International, Vol. 42, No. 10, pp. 1135 - 1143.

[3] LAMBERT-PERLADE, A., GOURGUES, A., PINEAU, A. (2004). Austenite to bainite phase transformation in the heat-affected zone of a high strength low alloy steel. In: Acta Materialia, Vol. 52, pp. 2337-2348.

[4] LiSCHEWSKI, I., GOTTSTEIN, G. (2011). Nucleation and variant selection during the $\alpha-\gamma-\alpha$ phase transformation in microalloyed steel. In: Acta Materialia, Vol. 59, pp. 1530-1541.

[5] SENTE SOFTWARE LTD. (2017), JMatPro the Materials Property Simulation Package., Version 9.0, United Kingdom
[6] KUČEROVÁ, L., JIRKOVÁ, H., KÁŇA, J. (2016). The Suitability of 42SiCr Steel for Quenching and Parti-tioning Process. In: Manufacturing Technology, Vol. 16, pp. 984-989. ISSN 1213-2489.

[7] AISMAN, D., JIRKOVA, H., RUBESOVA, K., JENICEK, S. (2016). Mini-Thixoforming of LowCarbon High-Alloy Steel. In: Manufacturing Technology, Vol. 16, pp. 845-849. ISSN 12132489.

[8] VOREL, I., JENÍČEK, Š., KÁŇA, J., IBRAHIM, K., KOTĚŠOVEC, V. (2016). Use of Optical and Electron Microscopy in Evaluating Optimization by Material-Technological Modelling of Manufacturing Processes In-volving Cooling of Forgings. In: Manufacturing Technology, Vol. 16, pp. 1383-1387, ISSN 1213-2489.

[9] VANDER VOORT, G. (2004). Metallography and microstructures. In: ASM Handbook, ASM International, Vol. 9. 